\title{
DISEASE \\ DATA \\ BOOK
}



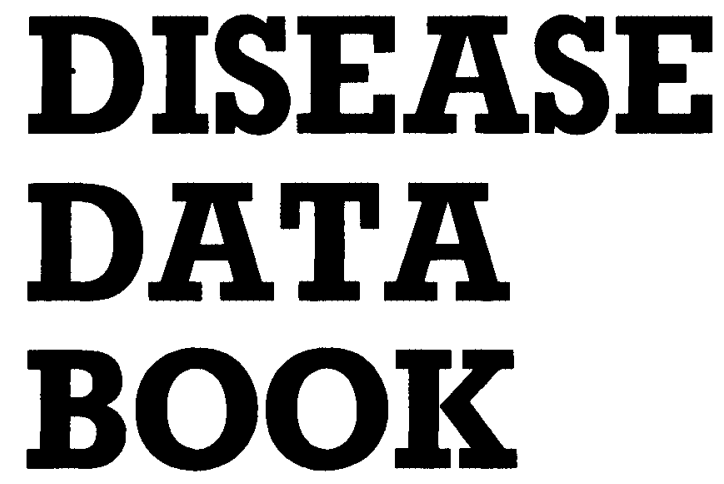

\title{
John Fry
}

General Practitioner, Beckenham, Kent

\section{Gerald Sandler}

Consultant Physician, Barnsley District General Hospital

\section{David Brooks}

General Practitioner, Manchester

\author{
WKAP ARCHIEF
}


Published in the UK and Europe by

MTP Press Limited

Falcon House

Lancaster, England

British Library Cataloguing in Publication Data

Fry, J.

Disease data book

1. Pathology 2. Medicine

I. Title II. Sandler, Gerald III. Brooks,

David, 1939

$616 \quad \mathrm{RB} 111$

ISBN-13: 978-94-010-8341-6 e-ISBN-13: 978-94-009-4149-6

DOI: $10.1007 / 978-94-009-4149-6$

Published in the USA by

MTP Press

A division of Kluwer Boston Inc

190 Old Derby Street

Hingham, MA 02043, USA

Library of Congress Cataloging in Publication Data

Fry, John.

Disease data book.

Bibliography: $p$.

Includes index.

1. Internal medicine-Handbooks, manuals, etc.

2. Medicine, Clinical-Handbooks, manuals, etc.

I. Sandler, Gerald, 1928- II. Brooks, David.

III. Title. [DNLM: 1. Diagnosis. Differential-handbooks.

2. Internal Medicine-handbooks. WB 39 F946d]

$\begin{array}{llll}\text { RC55.F75 } & 1985 & 616 & 85-24197\end{array}$

Copyright (C) 1986 MTP Press Limited

All rights reserved. No part of this publication may be reproduced, stored in a retrieval system, or transmitted in any form or by any means, electronic, mechanical, photocopying, recording or otherwise, without prior permission from the publishers. 


\section{CONTENTS}

Preface

1 High Blood Pressure

vii

2 Ischaemic Heart Disease

3 Strokes

4 Asthma

5 Chronic Bronchitis

6 Catarrhal Children

7 Glandular Fever (Infectious Mononucleosis)

8 Peptic Ulcers

9 Gallstones

10 Irritable Bowel Syndrome (IBS)

11 Ulcerative Colitis

12 Diverticular Disease

180

13 Diabetes

194

14 Epilepsy

206

15 Multiple Sclerosis

223

16 Migraine

247

17 Parkinsonism

267

18 Rheumatoid Arthritis

19 Low Backache

292

20 Urinary Tract Infections

318

21 Pregnancy

337

357

22 Cancers

362

References

395

Index 


\section{PREFACE}

Here we offer a new approach to understanding and managing common medical conditions. With the needs of our readers in mind we present clearer, more extensive and more expansive views on them.

Traditional medical textbooks are wordy tomes with well worn patterns dealing in set order with 'causes, symptoms and signs, diagnosis and treatment'. They offer formal instant snapshots of diseases.

We have devised an economic synoptic style, and we have endeavoured to give a comprehensive and an on-going long term move picture of each condition and to relate this to the analysis of symptoms and signs, to diagnostic assessment and to management and treatment.

We have selected 22 important conditions and for each have followed the same sequence of questions and answers:

- What is it?

giving a brief summary of the current understanding of the nature of the condition.

- Who gets it when?

showing the age-sex distributions and influence of other factors such as social class, international comparisons, and their likely frequency in general practice and at the district general hospital.

- What happens?

analysing the significance of symptoms and signs, the likely course and outcome and how these influence care.

- What to do?

an appreciation of the nature and presentation of the condition, and their relevance to diagnosis and management.

Our style and thinking have developed from experience with our previous books: Common Diseases (Fry, J., MTP, 1985), Common Medical Problems (Sandler, G., MTP, 1984) and NHS Data Book (Fry, J., Brooks, D., and McColl, I., MTP, 1984). As general practitioners and as a consultant physician in a district general hospital, we are aware of the real importance of being able to obtain a clear appreciation of our common problems in as easy and as quick a way as possible. Hence our rapid-read method, style and approach. We have enjoyed the challenge of putting the material together and we have all learnt much from each other. We hope that our readers too will enjoy and learn from our efforts. 
To whom do we dedicate our book? We believe that all medical students, postgraduate trainees and clinicians will find it of value, as will our colleagues in associated para-medical professions.

John Fry

Gerald Sandler

David Brooks

\section{Acknowledgements}

G. S: I am greatly indebted to my secretary, Christine Green, who worked so indefatigably and efficiently in typing the manuscript. I would like to thank Philip Hickson and Neil Wimpenny for their help in the production of some of the illustrations. I would also like to thank sincerely my very understanding wife, Ella, who continues to have inexhaustible patience with my writing and with the inevitable neglect that it entails. 